\title{
Thyroid Transcription Factor - 1 (TTF-1) Immunoexpression in Thyroid Carcinoma with Follicular Origin
}

\section{AMADEUS DOBRESCU ${ }^{1 \#, ~ C R I S T I ~ T A R T A ~}{ }^{1 \#,}$ MARIOARA CORNIANU ${ }^{2 *}$, CODRUTA LAZUREANU ${ }^{2}$, IOANA GOLU ${ }^{3}$, SONIA TANASESCU ${ }^{4 \#,}$ MIHAELA IACOB ${ }^{2}$, DAN BREBU ${ }^{1}$, ALEXANDRU ISAIC ${ }^{1}$, ROBERT BARNA ${ }^{2}$, FULGER LAZAR ${ }^{1}$}

${ }^{1}$ Victor Babes University of Medicine and Pharmacy, Faculty of Medicine, Surgery Department II, 2 Eftimie Murgu Sq., 300041, Timisoara, Romania

${ }^{2}$ Victor Babes University of Medicine and Pharmacy, Faculty of Medicine, Department of Pathology, 2 Eftimie Murgu Sq., 300041, Timisoara, Romania

${ }^{3}$ Victor Babes University of Medicine and Pharmacy, Faculty of Medicine, Department of Endocrinology, 2 Eftimie Murgu Sq., 300041, Timisoara, Romania

${ }^{4}$ Victor Babes University of Medicine and Pharmacy, Faculty of Medicine, Pediatrics Department II, 2 Eftimie Murgu Sq., 300041, Timisoara, Romania

\begin{abstract}
Differentiated thyroid carcinomas are heterogeneous diseases with clinical and morphological features insufficient to predict their clinical behavior. The expression of tissue-specific transcription factors that control differentiated phenotype can be an additional method in evaluating the aggressiveness of a tumor, when differentiation markers and malignant phenotype of tumor cells are inconclusive. The expression of thyroid transcription factor-1 (TTF-1) is limited to thyroid follicular cells; it is a nuclear protein expressed in the epithelial cells of the thyroid, lungs and diencephalon. Using the monoclonal mouse antibody, clone 8G7G3/1, we examined the immunohistochemical expression of TTF-1 protein in 26 thyroid carcinomas (22 papillary carcinomas - PTC, 2 follicular carcinomas - FTC, 2 anaplastic carcinomas - AC), 4 follicular adenomas - FA, 10 benign thyroid lesions as underlying diseases (multinodular goiter - 3, Hashimoto thyroiditis - 3, Graves Basedow disease - 4) and sections of normal thyroid tissue, assessing the possible correlations with clinical and morphological features, as well as patient outcomes.TTF-1 nuclear expression was identified in 75\% of benign thyroid lesions and 18/26 (69.23\%) carcinomas. We noted TTF-1 nuclear expression in 68.18\% of PTC (10\% being associated with recurrent disease) and the absence of immunoreaction in $31.82 \%$ of PTC without recurrent disease. In patients with PTC, the risk of recurrence was significantly associated with the presence of nuclear TTF-1 expression in the primary tumor ( $p<0.001)$, but was not influenced by the type of surgery performed ( $p>0.05$ ) or patients' age. TTF-1 nuclear expression did not correlate with patients' gender, tumor size, extent of disease at the moment of diagnosis and multifocal tumors ( $p>0.05)$. TTF-1 nuclear reactivity can be elevated in differentiated thyroid tumors (PTC and FTC) with aggressive clinical behavior that will develop recurrent or persistent disease. In anaplastic thyroid carcinomas with fast growth rate, immunoreactivity for TTF-1 and Ki-67 can offer useful information for tumor cell differentiation, while in the case of a mixed thyroid tumor it helps in distinguishing between well differentiated and undifferentiated/anaplastic areas.
\end{abstract}

Keywords: thyroid carcinoma, thyroid transcription factor (TTF-1), immunohistochemistry

\section{Introduction}

Differentiated thyroid carcinomas are heterogeneous diseases with clinical and morphological features insufficient to predict their clinical behavior. The expression of tissue-specific transcription factors that control differentiated phenotype can be an additional method in evaluating the aggressiveness of a tumor, when differentiation markers and malignant phenotype of tumor cells are 
inconclusive. Transcription factors are nuclear proteins that have an important role in regulating gene expression, thereby determining and maintaining cellular phenotype. Thyroid transcription factor-1 (TTF-1) is a $38 \mathrm{kDa}$ protein (in the NKx2 family of DNA-binding proteins) that is expressed during embryonic development in the thyroid, diencephalon and respiratory epithelium. Numerous studies have shown that antibodies to TTF-1 can be very useful reagents in diagnostic pathology. It is important to realize that only nuclear immunoreactivity to TTF-1 represents "true" reactivity, and for the purposes of diagnosis, any cytoplasmic reactivity should be ignored (similar to certain other nuclear antigens such as ER and PR) [1]. In the mature thyroid grand, TTF-1 regulates gene expression of thyroglobulin (Tg), thyroid peroxidase (TPO), sodium-iodide symporter (NIS), as well as thyroid stimulating hormone receptor (TSH-R) in thyroid cells. TSH regulates thyroid function and growth, various observations suggesting a potential interaction between TSH and TTF-1. It is supposed that TSH-R activity can elevate TTF-1, the latter being expressed differently in benign and malignant thyroid diseases. TTF-1 mRNA is always detected in papillary carcinomas and it is absent in anaplastic carcinomas [2]. Little information is known about the nuclear localization of TTF-1 in benign and malignant thyroid tumors. Previous studies demonstrated nuclear TTF-1 expression in follicular adenomas, well-differentiated thyroid carcinomas and the absence of TTF-1 expression in most undifferentiated thyroid carcinomas. De Vita et al. (1998) showed that ret/PTC-1 oncogene interrupts differentiated thyroid phenotype by deteriorating TTF-1 function at post-translational level [3].

In the thyroid gland, TTF-1 is expressed immunohistochemically (IHC) by normal thyroid tissue and thyroid adenomas, differentiated thyroid carcinomas with follicular origin and medullar carcinoma. Over 95\% of follicular, papillary and insular thyroid carcinomas show TTF-1 expression, while the reactivity of Hurthle cell tumors to TTF-1 is between 20-75\%. TTF-1 immunoreactivity is reduced in poorly differentiated carcinomas and it is usually absent in undifferentiated/anaplastic carcinomas with reduced Tg expression [1].

\section{Materials and methods \\ Presentation of studied cases}

This paper represents a retrospective analysis of a group of 40 patients with endocrine symptoms, investigated (clinically, ultrasonographically, scintigraphically) and operated for non-neoplastic thyroid lesions and thyroid tumors. The cases were selected from the casuistry of the Pathology Department (PD) of the County Clinical Hospital of Timisoara (CCHT) and came from patients operated for various thyroid lesions in the Surgery Departments of CCHT between January 2010 and June 2012. Clinical data were obtained after reading patients' records. For each patient included in the study, we assessed clinical and pathological features, such as: age and gender of the patients, size of the primary tumor, location of the tumor, histological type of the tumor, multifocal dissemination, clinical staging, thyroid capsule infiltration and number of affected lymph nodes. The study included only thyroid tumors derived from follicular cells (cases of medullary carcinoma and thyroid lymphoma being excluded).

\section{Morphological diagnostic methods}

Primary processing of surgical resection pieces was made after their sectioning, fixation in $10 \%$ formalin for 24-48 h, paraffin inclusion using the standard technique (washing, dehydration, clearing, inclusion), followed by sectioning at $4-5 \mu$ (multiple seriated sections being made for each case). The usual morphological examination was made on sections stained with hematoxylin-eosin (HE) using the standard technique (applied on all studied cases), that helped with establishing a histopathological diagnosis, classifying the lesions and dividing them into groups, as well as with establishing the histological type of the tumor. The extent of the disease at the moment of diagnosis was assessed using the criteria of De Groot et al (1990). Thus, the tumors from the first group were limited to the thyroid gland, the second group included tumors involving regional lymph nodes, group III comprised tumors extended beyond the thyroid capsule and group IV included lesions with distant metastasis. Recurrences 
were defined as a new tumor (proven by biopsy or radioactive iodine intake) in any patient that did not have a lesion for at least 4 months.

\section{Immunohistochemistry}

To analyze the hypothesis stating that TTF-1 is expressed differently in benign and malignant thyroid lesions, we examined the immunohistochemical (IHC) expression of TTF-1 protein in 26 thyroid carcinomas (22 papillary carcinomas - PTC, 2 follicular carcinomas - FTC, 2 anaplastic carcinomas AC), 4 follicular adenomas - FA, 10 benign thyroid lesions as underlying diseases (multinodular goiter - 3, Hashimoto thyroiditis - 3, Graves Basedow disease - 4) and sections of normal thyroid tissue, assessing the possible correlations with clinical and morphological features, as well as patient outcomes. For the IHC study, a representative block was selected in each case, from which additional sections were cut $(4 \mu \mathrm{m}$ thick) and mounted on Superfrost Ultra Plus slides or silanized in order to avoid their detachment during pre-treatment processes. IHC reactions were made on sections $4 \mu \mathrm{m}$ thick, using the monoclonal antibody anti-TTF-1, clone 8G7G3/1, with EnVision-HRP visualization system. For the blocking of endogenous peroxidase, deparaffinated sections were treated with $3 \%$ hydrogen peroxide $\left(\mathrm{H}_{2} \mathrm{O}_{2}\right)$ in methanol for 10 minutes; then, they were immersed in citrate buffer (pH9) and heated in a microwave oven for 20 minutes in order to enhance antigen retrieval. Sections were incubated for 15 minutes with the primary antibody anti-TTF-1 (clone 8G7G3/1) RTU and then treated for 20 minutes with the secondary antibody - Ultra Vision (HRP polymer), followed by visulization of the reaction with 3,3'-diaminobensidine (DAB) chromogen and a mild counter-staining of the nuclei using Meyer haematoxylin. For the internal positive control of the reaction, we included a TTF-1 positive small cell pulmonary carcinoma and for the negative control, the same staining protocol was followed, but with the omission of the primary antibody.

In the two cases of anaplastic carcinomas, we analyzed the IHC expression of Ki-67 antigen, using the pre-diluted monoclonal antibody, clone MIB-1, LSAB technique with boiling pre-treatment (in Retrieval solution for 60 minutes at $90^{\circ}$ ) and visualization with DAB. The final reaction product has a brown color and nuclear localization; thyroglobulin expression was assessed using the monoclonal antithyroglobulin (Tg) antibody, clone DAK-Tg6.

\section{Evaluation of immunostaining}

The cells were considered TTF-1 positive when we identified a nuclear brown staining pattern. We considerd as "true" TTF-1 reactivity only nuclear TTF-1 immunoreactivity; for diagnostic purposes we ignored any cytoplasmic reactivity. Nuclear TTF-1 immunoreactivity was quantified as follows: grade 0 (absent), grade 1 (minimal), grade 2 (moderate) or grade 3 (intense) based on staining features from most of the tumors. TTF-1 immunoreaction intensity was assessed in each case by determining the percentage of positivity from 500 cells. The quantification of Ki-67 immunoreaction was made by assessing the Ki-67 proliferation index (PI Ki-67), expressed as a percentage result of the number of Ki67 positive cells, per 500 cells.

The data were statistically analyzed using the Past software, Fisher's exact test incorporating the Yates correction for continuity. The differences observed were considered statistically significant for values of $\mathrm{p}<0.05$.

Ethics: All procedures used in this study (histopathological analysis and microscopic images from the slides) had patient approval and a written informed consent was signed for the use of biological material in research studies (Annex no.4 for the 112/2013 law). For the study of cases and access to the database, we had consent from the heads of PD and the Clinics involved in this study.

\section{Results and discussions}

In normal thyroid tissue, the degree of TTF-1 nuclear staining was 1 . TTF-1 nuclear staining was similar in the group of benign thyroid lesions. TTF-1 nuclear expression was identified with similar intensity in $75 \%$ of benign thyroid lesions and 18/26 (69.23\%) carcinomas (fig. 1). PTC and FTC showed 
an elevated percentage of nuclear positivity, higher than the one observed in nodular hyperplasia and follicular adenoma. TTF-1 nuclear expression had a similar intensity (medium) in PTC and FTC, as compared to non-malignant thyroid lesions. The anaplastic carcinomas that we analyzed did not express TTF-1.

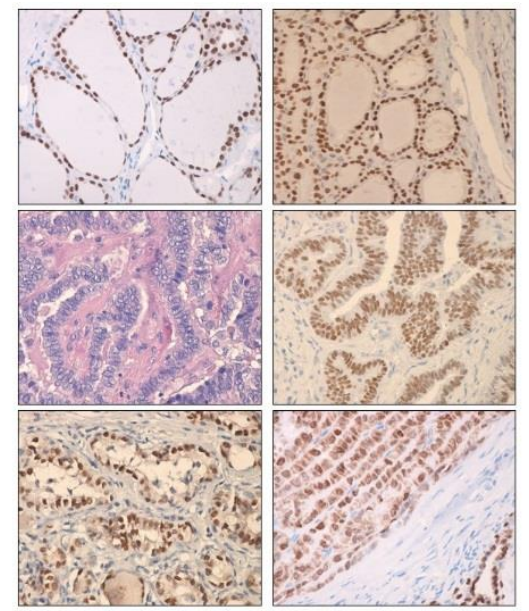

Figure 1. TTF-1 nuclear expression: goiter TTF-1; thyroid follicular adenoma TTF-1; PCT H\&E section; PTC TTF-1; PTC - follicular variant TTF-1; tall cell PTC TTF-1 - staining $(200 x)$

Tables 1 and 2 show clinical data and results of nuclear expression of TTF-1 in patients with welldifferentiated thyroid carcinoma (PTC, FTC). Patients with PTC (17 women and 5 men) had a mean age of 35.5 years (between 21 and 54 years of age) and a mean tumor size of $2.4 \mathrm{~cm}(0.5-4.4 \mathrm{~cm})$. Only one patient was previously exposed to irradiation therapy for lymphoma. TTF-1 nuclear expression was detected in 15/22 (68.18\%) PTC, 3 of the patients (20\%) developing recurrent disease and it was absent in $7 / 22(31.82 \%)$ PTC with no recurrent disease. We did not notice significant differences between patients with PTC, with present or absent TTF-1 nuclear expression and the gender of the patients, tumor size, extension of the disease at the moment of diagnosis and multifocal tumors ( $>0.05)$. In patients with PTC, we analyzed the impact of TTF-1 nuclear expression in the primary tumor on the risk of recurrence. Disease recurrence was significantly associated with the presence of TTF-1 nuclear expression in the primary tumor ( $\mathrm{p}<0.001)$, but it was not influenced by the type of surgical intervention ( $>0.05$ ). Recurrent disease developed in 3 of the 15 patients (20\%) with TTF-1 nuclear expression. The 7 patients without TTF-1 nuclear expression stayed disease-free for the follow-up period of 10 months.

Table 1. The relationship between ttf-1 nuclear expression and clinical Parameters in patients with PTC

\begin{tabular}{|c|c|c|c|c|c|c|}
\hline $\begin{array}{c}\text { Age } \\
\text { (years) }\end{array}$ & Size (cm) & Group* & Focal & Surgery & $\begin{array}{c}\text { I-131 } \\
\text { ablation }\end{array}$ & $\begin{array}{l}\text { Recurrence/ } \\
\text { persistence }\end{array}$ \\
\hline \multicolumn{7}{|c|}{ PTC with present TTF-1 nuclear expression $(n=15 / 22 ; 68.1 \%)$} \\
\hline 30.3 & 2.5 & $\begin{array}{l}\mathrm{I}=9 * * \\
\mathrm{II}=3 \\
\mathrm{III}=2 \\
\mathrm{IV}=1\end{array}$ & $\begin{array}{c}\text { Unifocal=9 } \\
\text { Multifocal=5 } \\
\text { DI-1 }\end{array}$ & $\begin{array}{c}\text { Total }=7 \\
\text { Subtotal }=4 \\
\text { Lobectomy }=3 \\
\text { UD }=1\end{array}$ & $\begin{array}{c}\text { Yes }=11 \\
\mathrm{No}=2 \\
\mathrm{UD}=2\end{array}$ & $\begin{array}{c}3(\%) \\
(p<0.001)\end{array}$ \\
\hline \multicolumn{7}{|c|}{ PTC with absent TTF-1 immunoreactivity $(n=7 / 22 ; 31.9 \%)$} \\
\hline 33.1 & 2.1 & $\begin{array}{c}\mathrm{I}=3 \\
\mathrm{II}=3 \\
\mathrm{III}=1 \\
\mathrm{IV}=0\end{array}$ & $\begin{array}{c}\text { Unifocal=5 } \\
\text { Multifocal=2 }\end{array}$ & $\begin{array}{c}\text { Total }=3 \\
\text { Subtotal }=2 \\
\text { Lobectomy }=1 \\
\text { UD }=1\end{array}$ & $\begin{array}{l}\mathrm{Yes}=5 \\
\mathrm{No}=1 \\
\mathrm{UD}=1\end{array}$ & $0(0 \%)$ \\
\hline
\end{tabular}

The impact of TTF-1 nuclear expression on recurrence was not influenced by patients' age, the mean age of patients with recurrent disease being close to that of the patients with no recurrent disease. 
Patients with FTC (table 2) (4 cases) had a mean age of 43.5 years (between 42 and 47 years old) and a mean tumor size of $2.1 \mathrm{~cm}(1.8-2.5 \mathrm{~cm})$. None of the patients with FTC had previous radiation exposure. Statistical analysis did not demonstrate a significant relationship between FTC patients with present or absent TTF-1 nuclear expression and multifocal tumors ( $p>0.05)$; the impact on disease recurrence was influenced by the presence of TTF-1 nuclear expression $(\mathrm{p}<0.001)$. In order to draw some pertinent conclusions regarding the clinical relevance of TTF-1 nuclear expression, additional studies on larger groups of patients with FTC are necessary.

Table 2. Relationship between ttf-1 nuclear expression and clinical parameters in patients with FTC

\begin{tabular}{|c|c|c|c|c|c|}
\hline $\begin{array}{c}\text { Age } \\
\text { (years) }\end{array}$ & Size $(\mathbf{c m})$ & Focal & Surgery & $\begin{array}{c}\text { I-131 } \\
\text { ablation }\end{array}$ & $\begin{array}{l}\text { Recurrence/ } \\
\text { persistence }\end{array}$ \\
\hline \multicolumn{6}{|c|}{ FTC/HCC with present TTF-1 nuclear expression $(n=3)$} \\
\hline 44.5 & 2.2 & $\begin{array}{c}\text { Unifocal }=2 \\
\text { Multifocal }=1\end{array}$ & $\begin{array}{c}\text { Total }=2 \\
\text { Subtotal }=1\end{array}$ & 3 cases & $1(12.5 \%)$ \\
\hline \multicolumn{6}{|c|}{ FTC/HCC - absent TTF-1 immunoreactivity $(n=1)$} \\
\hline 47 & 1.9 & Unifocal=1 & Total $=1$ & 1 case & $0(0 \%)$ \\
\hline
\end{tabular}

In the two anaplastic thyroid carcinomas with rapid growth, we investigated the expression of TTF1, thyroglobulin and KI-67, comparing tumor areas with papillary/follicular pattern and anaplastic areas. We noted TTF-1 nuclear reactivity and positive thyroglobulin expression in well differentiated tumor cells (with papillary/follicular pattern) and negative immunoreactions in the anaplastic areas of the tumor. We consider that TTF-1 and Ki-67 reactivity can offer useful information for the differentiation of thyroid tumor cells, in the case of a mixed thyroid tumor, helping the distinction between well differentiated areas and non-differentiated/anaplastic ones. In anaplastic areas, PI Ki-67 was 60.5\%; we identified Ki-67 reactive lymphocytes scattered between Ki-67 positive tumor cells.

Transcription factors are nuclear proteins with an important role in gene expression regulation, in determining and maintaining cellular phenotype [1]. The three thyroid specific transcription factors, NKX2-1 (also called TTF1, TITF1, T/EBP or NKX2.1), FOXE1 (also called TTF2 or TITF2) and PAX8 are members of the family of homeodomain-containing transcription factors, being essential in thyroid function. These factors activate gene transcription that code for thyroglobulin, thyroid peroxidase, thyrotropin receptor and sodium/iodide symporter, proteins that are essential for the synthesis of thyroid hormones [5-8].

Thyroid transcription factor-1 (TTF-1) is a protein of the homeodomain-containing gene family. This type of protein has an important role in development processes, cell growth and differentiation $[9,10]$, being essential for the morphogenesis of the thyroid gland, lungs and the ventral parts of the brain $[11,12]$, with a major role in thyroid gene transcription and maintaining the differentiated thyroid phenotype [2]. In the fetus, TTF-1 expression appears early during organogenesis and it is responsible for inducing the differentiated thyroid phenotype $[13,14]$. TTF-1 is transcriptionally active in the human thyroid gland and it is present in the nucleus of thyroid follicular cells [15]. Although numerous studies support the utility of anti-TTF-1 antibodies as useful markers in diagnosing thyroid pathology, few studies are known to examine the nuclear localization of TTF-1 in benign and malignant thyroid tumors. In the thyroid gland, TTF-1 is expressed by benign tissues, malignant tumors with follicular origin and medullary carcinoma. TTF-1 immunoreactivity is low in poorly differentiated carcinomas and absent in anaplastic carcinomas [16]. The ProPath laboratory describes TTF-1 expression in over 95\% of follicular, papillary and insular thyroid carcinomas, in a similar percentage in medullary carcinomas and 
in $20-75 \%$ of Hurthle cell tumors, adding that the reactivity of Hurthle cell tumors for TTF-1 is somewhat lower and most anaplastic thyroid carcinomas are TTF-1 negative. In other studies, TTF-1 is identified in $96 \%$ of papillary carcinomas, $100 \%$ of follicular carcinomas, $20 \%$ of Hurthle cell tumors and $90 \%$ of medullary carcinomas, while anaplastic carcinomas are TTF-1 negative [17-20].

Differentiated thyroid carcinomas maintain a differentiated phenotype that includes iodide capitation and $\mathrm{Tg}$ synthesis. It is considered that this process is interrupted by alteration of the transcription of tissue-specific differentiation factors [21]. Analyzing only the well differentiated thyroid carcinomas, Fenton CL et al. (2001) noted nuclear TTF-1 expression in $77 \%$ of benign lesions and in $69 \%$ of malignant ones, with similar reaction intensity in both types of lesions $(1,1 \pm 0,19$ vs. $1,0 \pm 0,1 ; p=0,59)$. The authors describe recurrent or persistent disease in well differentiated carcinomas (in $23 \% ; 8$ out of 35 PTC and in 12.5\%; 1 of 8 FTC) with nuclear TTF-1 expression and only $6 \%$ (1 of 18) of patients with PTC TTF-1 negative ( $\mathrm{p}=0.06$ ) [2]. The impact of TTF-1 nuclear expression on recurrence is not influenced by the age difference of patients. These results suggest that TTF-1 nuclear expression can be important for the development of recurrences of well differentiated thyroid carcinomas, this affirmation being indirectly supported by previous studies that demonstrated a reduced risk of recurrence among patients with TSH suppression [22-24]. Similar results are reported by Katoh et al. (2000) who examined the nuclear localization of TTF-1 in benign and malignant thyroid tumors; the authors described nuclear TTF-1 immunoreactivity in most well differentiated benign and malignant thyroid tumors (in 15 follicular adenomas, 13 PTC and 5 FTC) and the absence of TTF-1 expression in 3 of the 4 nondifferentiated thyroid carcinomas [9]. These observations suggest the maintenance of TTF-1 nuclear expression in benign and well differentiated malignant tumors. The results do not show a significant relationship between TTF-1 reactivity and the expression of Tg or TPO genes and does not offer clinical relations about the risk of tumor recurrence.

In our study, we examined IHC the nuclear expression of TTF-1 in various benign and malignant thyroid lesions (30 thyroid tumors derived from follicular cells, 10 benign thyroid lesions and 2 normal thyroid tissues), assessing the impact of TTF-1 expression on the clinical behavior of thyroid carcinoma. We identified TTF-1 immunoreactivity in $75 \%$ of benign thyroid lesions and 18/26 (69.23\%) carcinomas. 15/22 (68.18\%) of patients with PTC presented TTF-1 nuclear expression. Recurrent disease was observed in $3(20 \%)$ of the 15 patients with PTC who expressed nuclear TTF-1, as compared to the absence of recurrence in the 7 patients without TTF-1 nuclear expression who stayed disease-free for the follow-up period of 10 months. Recurrent disease was significantly associated with the presence of TTF-1 nuclear expression in the primary tumor $(\mathrm{p}<0.01)$. For patients with PTC, the intensity of TTF1 nuclear staining got higher with age, but did not correlate significantly with patients' gender, tumor size, extent of the disease at the moment of diagnosis and multifocal tumors ( $p>0.05)$. 3 FTC expressed TTF-1, the total number of patients being too low to draw conclusions about the nuclear expression of TTF-1.

\section{Conclusions}

TTF-1 is a marker used in diagnostic pathology, useful for the identification of thyroid carcinomas; it can be considered a necessary marker for the expression of differentiated thyroid phenotype and it can distinguish differentiated thyroid carcinomas from anaplastic lesions. The expression of TTF-1 protein with nuclear pattern is detected in most benign thyroid lesions and in well differentiated thyroid carcinomas (PTC and FTC). TTF-1 nuclear reactivity can be elevated in differentiated thyroid carcinomas with clinically aggressive behavior, which will develop recurrent disease. Assessment of the impact of TTF-1 nuclear expression on the clinical evolution of FTC needs additional studies on larger groups of patients with FTC. In anaplastic thyroid carcinomas with rapid growth, TTF-1 and Ki-67 immunoreactivity can offer useful information for the differentiation of thyroid tumor cells and in the case of a mixed thyroid tumor, it helps distinguishing between well differentiated areas and those that are undifferentiated/anaplastic. 


\section{References}

1. Propath Laboratory. Thyroid transcription factor-1 (TTF-1). Focus on Immunohistochemistry, 2001.

2. FENTON, C.L., PATEL, A., BURCH, H.B., TUTTLE, R.M., FRANCIS, G.L., Ann Clin Lab Sci., 31, no. 3, 2001, p. 245.

3. DE VITA, G., ZANNINI, M., CIRAFICI, A.M., MELILLO, R.M., DI LAURO, R., FUSCO, A., SANTORO, M., Cell Growth Differ., 9, 1998, p. 97.

4. DE GROOT, L., KAPLAN, E., MCCORMICK, M., STRAUSS, F., J Clin Endocrinol Metab., 71, 1990, p. 414.

5. NGAN, E.S., LANG, B.H., LIU, T., SHUM, C.K., SO, M.T., LAU, D.K., LEON, T.Y., CHERNY, S.S., TSAI, S.Y., LO, C.Y., KHOO, U.S., TAM, P.K., GARCIA-BARCELÓ, M.M., J Natl Cancer Inst., 101, no. 3, 2009, p. 162.

6. TAKAHASHI, M., SAENKO, V.A., ROGOUNOVITCH, T.I., KAWAGUCHI, T., DROZD, V.M., TAKIGAWA-IMAMURA, H. et al., Hum Mol Genet., 19, no. 12, 2010, p. 2516.

7. EBERHARDT, N.L., GREBE, S.K.G., MCIVER, B., REDDI, H.V., Mol Cell Endocrinol., 321, no. 1, 2010, p. 50.

8. KIMURA, S., J Thyroid Res., 2011, 2011; 1-8.

9. KATOH, R., KAWAOI, A., MIYAGI, E., LI, X., SUZUKI, K., NAKAMURA, Y., KAKUDO, K., Mod. Pathol., 13, 2000, p. 570.

10. ZIAD, E.A., RUCHALA, M., BREBOROWICZ, J., GEMBICKI, M., SOWINSKI, J., GRZYMISLAWSKI, M., Folia Histochem Cytobiol., 46, no. 4, 2008, p. 461.

11. LANZAFAME, S., CALTABIANO, R., PUZZO, L., CAPPELLANI, A., Virchows Arch., 49, 2006, p. 129.

12. ESPADINHA, C., SILVA, A.L., CABRERA, R., BUGALHO, M.J., J Oncol., 2012, 2012; 1-6.

13. SUZUKI, K., MORI, A., LAVARONI, S., MIYAGI, E., ULIANICH, L., KATOH, R., KAWAOI, A., KOHN, L.D., Thyroid, 9, 1999, p. 319.

14. OHMORI, M., OHTA, M., SHIMURA, H., SHIMURA, Y., SUZUKI, K., KOHN, L.D., Mol Endocrinol., 10, 1996, p. 1407.

15. HOLZINGER, A., DINGLE, S., BEJARANO, P.A., MILLER, M., WEAVER, T.E., DILAURO, R., WHITSETT, J.A. Hybridoma, 15, 1996, p. 49.

16. BORDA, A., BERGER, N., Ghid de diagnostic în patologia endocrină, Ed. University Press Târgu Mureş, 2009, p. 137.

17. ORDONEZ, N.G., Adv Anat Pathol., 7, 2000, p. 123.

18. LAU, S.K., LUTHRINGER, D.J., EISEN, R.N., AIMM, 10, 2002, p. 97.

19. KATOH, R., MIYAGI, E., NAKAMURA, N., LI, X., SUZUKI, K., KAKUDO, K., KOBAYASHI, M., KAWAOI, A., Hum Pathol., 31, 2000, p. 386.

20. TATIC, S., Arch Oncol., 11, no. 3, 2003, p. 173.

21. ROS, P., ROSSI, D.L., ACEBRON, A., SANTISTEBAN, P., Biochimie, 81, 1999, p. 389.

22. MAZZAFERRI, E.L., Endocr Pract., 6, 2000, p. 469.

23. KEBEBEW, E., CLARK, O.H., World J Surg., 24, 2000, p. 942.

24. GORETZKI, P.E., SIMON, D., DOTZENRATH, C., SCHULTE, K.M., ROHER, H.D., World J Surg., 24, 2000, p. 913.

$\overline{\text { Manuscript received: } 29.12 .2019}$ 